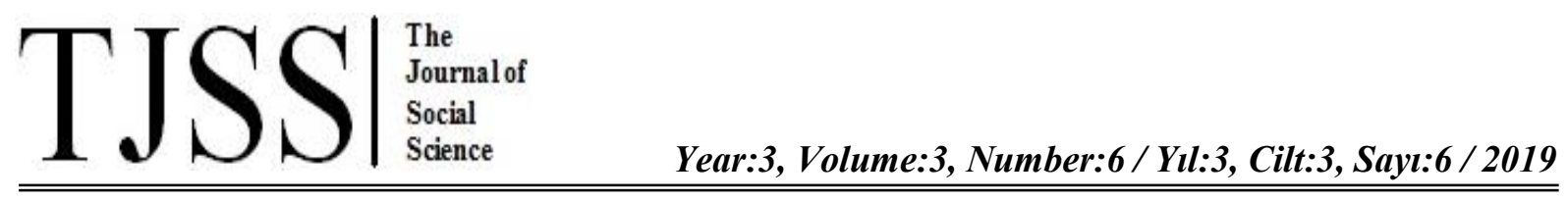

DOI Number: 10.30520/tjsosci.596617

\title{
A RESEARCH ABOUT RELATIONSHIP BETWEEN FASHION DESIGN AND FABRIC PARAMETERS
}

\author{
Şöhret AKTEPE DAL ${ }^{1}$
}

\begin{abstract}
Many factors depend on bringing out a successful design. One of the most important factors influencing clothing design is material selection. Choosing the right fabric increases the efficiency, creativity and quality of clothing design. Fashion fabric must have five main descriptive parameters: suitable material selection (natural or man-made fibres and etc.), main features (thickness, length and etc.), yarn properties (twist, hairness, yarn count, yarn irregularity and etc.), fabric construction (wet and dry heat treatment, structure, fabric drape, bending rigidity and etc.) and finishing process (colour, print and etc.). These parameters determine the performance of the final product and compose of the usage areas and product activity. In this study, the various applications, properties and influences of fabrics as clothing material are emphasized and presented on examples.
\end{abstract}

Key Words: Fabric, Fashion Design, Material, Texture, Form

\section{Introduction}

It should be considered functionality in the product, before aesthetics and silhouette. It is often ignored functionality with the concern of creating a better view. After research about product function, theme and project requirements should come design stage. Design product is consisted of a selected theme, concept, everything about to satisfy needs and execute actions. In the process of design, for being in less time and more qualified final product and collection must select suitable material. For these reasons, the aims of this article are to explain affecting factors the clothing design, creation, preparation collection, and material selection.

\section{Factors of Fashion Design}

Fashion design; It starts with the determination of colours, patterns, and texture and continues with the production of fibers and transformation into yarn and fabric. Processes of designing fashion products are listed as fabric, colour, pattern, accessory, model preparation, form measurement, clothing mold, prototype, the final product, collection, and mass production. The whole fashion design process is a creative movement for the final product.

Creativity is connected with subjectivity and fashion is interpreted as a creative vision and process. Wearability is a subjective concept and is directly related to the person.

\footnotetext{
${ }^{1}$ Dr. Öğretim Üyesi, Haliç Üniversitesi, sohretaktepe@ halic.edu.tr
} 
If a fashion design process is to succeed, it will be creativity and wearability are mutually interdependent If it is creativity and wearability are mutually interdependent, fashion design process would succeed all the time (Renfrew \& Renfrew 2016, s.16).

The designer should do research on every subject that may inspire his / her designs and as a result of these researches, he/she should create his / her designs based on a chosen topic or theme. In the second stage, he/she should begin to embody his ideas by preparing the colour and storyboard that includes the related materials. The designer should determine the fabrics and auxiliary materials he is planning to use and must first make a choice of colour, design, and material while preparing the colour and storyboard.

\subsection{Fabric}

The target material/fabric is selected from a wide variety of materials by analyzing the quality of the design by the designer to serve the meaning and purpose of the design. The material should be considered in connection with other factors affecting the design. Choosing materials that have previously been tested in the selection of materials makes the designer feel confident. However, the use of high value-added materials increases the competitiveness of designs. For this reason, the designer must follow the relevant developments and have up-todate knowledge by controlling the fabric information (Akpınarlı \& Bulat 2016, s. 167).

Fabric selection is one of the most important and cost-effective decisions in the development of design because half of the total production cost of a garment should be fabric cost. Furthermore, in addition to cost planning, the climatic characteristics of the season, season analysis, usage area of the clothing, gender and age group of the target population are the factors that affect the selection.

\subsection{Fabric Manipulation}

Manipulation is defined as the art of changing the texture, shape, view, colour of the fabric and making it different than it is. Manipulation is carried out with different techniques and materials such as sewing (draping, shirring, rib, pipe, gathering and etc.) embroidery (by hand-made or machine), prepared material (cord, ribbon, lace and etc.) and technological methods (laser cut) (Gürsoy, 2010). Choosing the appropriate one from different fabric manipulation techniques will determine the aesthetic strength of the design.

\subsection{Balance on the Basis of Colour, Texture and Form}

Colour is defined as the meaning of the dictionary, light is sensation depending on its own structure or reflection from the objects (tdk. gov.tr, 2019). The texture is called the appearance and/or feel of the surface of an artwork that is connected to the structural feature. In addition, it is a condition of a particular colour or shape. The form is called a mass or volume occupying space. In order to achieve this illusion, artists use techniques such as modelling or scanning. The theme is integrated with colour, texture, and form. Once the fabrics are selected and the desired colours, texture and form are decided for the collection, the main design drawings are created and the design process continues.

\subsection{Using of Dye and Print Design}

The compounds used in the colouring of textile products and connected to the textile surface by chemical bonds are called dyes. As a result of dying, chemical bonding occurs between 
textile material (fiber, yarn, fabric, etc.) and dyestuff. While painting paints any part of the fabric to colour, only certain areas of the fabric are dyed in printing. In terms of application, printing methods are divided into three main groups: direct, abrasion and reserve. This methods of grouping change on the desired print effect, the fashion and the economics of the method to be applied (Yurdakul \& Atav 2004).

\section{Main Descriptive Parameters of Fashion Fabric}

\subsection{Suitable Material Selection}

Fashion fabric has some distinctive properties such as textile fibers. These fibers could be spun into a yarn and form a fabric surface by various methods as weaving or knitting. Fibers are classified as natural and artificial according to sources from which material is obtained. In the garment design, the choice of suitable fiber-containing fabric to the place of use will provide the advantage of using the final product. Textile fibers are divided into two categories such as natural and manmade. Natural fibers are produced by plants, animals, and minerals. They are also biodegradable, environment-friendly and sustainable. Fibers derived from plants are composed of a source of seed (cotton), bast (flax, hemp, jute, ramie, kenaf), leaf (sisal, Manila, New Zealand flax) and nut (coco). Fibers derived from animals are divided into two source categories: hair (wool-sheep, cashmere, camel, mohair, alpaca, llama, and vicuna) and secretion (silk). Fibers derived from mineral is asbestos. Manmade fibers have consisted of regenerated polymer and synthetic fibers. They are formed polymer structure by chemical synthesis or natural sources and reproduced after passing through a spinnet to form fibers. Regenerated polymers are composed of regenerated cellulose (viscose, cupro, modal, lyocell), cellulose esters (acetate), regenerated protein (casein, vegetable protein) and miscellaneous (rubber). Synthetic fibers are a polyolefin (polyethylene, polypropylene, polytetrafluoroethylene), polyvinyl (acrylic, modacrylic, polyvinylidenechloride, polyvinyl chloride, polyvinyl alcohol), polyamide (nylon, perlon), polyester (terylen, trevira) and polyurethane (lycra).

\subsection{Main Features}

The consumer takes care of the beneficialness, usefulness, and ease of storage of the product. It is necessary to know which fiber to use and the basic properties of this fiber according to the place and purpose of the fabric. Main features of fibers are composed of length (staple and filament), thickness, brightness, spinning, durability, elongation, flexibility, density (volumetric and linear), thermal exposure (thermoplastic, non-thermoplastic), lightfastness and electrically (Baser, 2002, s. 12).

\subsection{Yarn Properties}

Yarn properties are significant in terms of fashion fabric. The crucial yarn properties to be considered would be yarn count, thickness, elasticity, elongation, yarn strength, hairiness, maturity, cleanliness, sinuosity, evenness and flexibility. These factors are affected sensorial comfort, quality, usage areas, aesthetic perception, and performance properties. Types of yarns are divided into two categories: staple and filament yarn. Filament fibers are long-continuous, endless-length fibers, while staple has a short and finite length. Manmade fibers can be cut to form a staple fiber after being produced in the form of a continuous filament. 


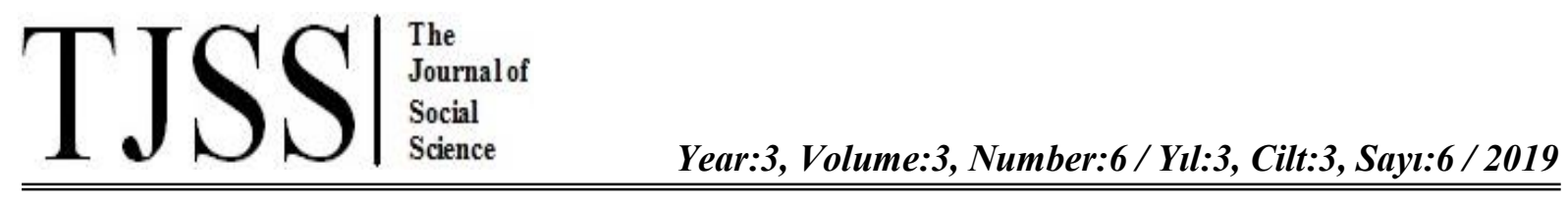

\subsection{Fabric Construction}

The fabric is a structure obtained by combining the textile fibers with a smooth surface and a uniform thickness. It has to form a thin, flexible and durable texture. Fabric structures are divided into three categories; woven, knitted and non-woven surfaces. A woven fabric is formed by the interlacement of two sets of yarns with 90-degree angle. Woven structures are consisted of weft and warp threads. Weft threads run transversely across the fabric and warp threads run longitudinally along the fabric.

The knitted technique is classification from the yarn direction of stitches. The compose of fabric with knitting is the fastest system in fabric techniques. In addition, the fabrics produced by the knitting system are more flexible, more elastic, softer and fuller than the other textile surfaces. Knitting techniques are classification as weft and warp knitted. Weft knitting is named as of on the technique of surface creation which connection of the loops in the cross direction according to the single yarn supply system. Warp knitting is named as of on the technique of surface creation which connection of the loops in the transverse direction according to the multi yarn feeding system. The level of extensibility of warp knitted fabrics is less than that of weft knitted fabric. For this reason, it is difficult to obtain shaped products from warp knitted fabrics than weft knitted fabric. Additionally, knitted fabrics have higher dehumidification properties, drawing tendency and drapability than woven fabrics. The nonwoven surface is the name given to the special texture or surface formed by attaching the nonthreaded fibers to each other by various methods. It is possible to see a wide range of nonwoven products in the agricultural sector, filtration, composite, and the automotive industry, medicine, space, and defense industry. Non-woven products are widely used in fashion design as interlining and felt.

\subsection{Finishing Process}

Finishing process is called to improve the appearance (dyeing, printing, brightening, delustring and etc.) attitude (softening, hardening, lubricate, etc.) and usage properties (easyironing, non-flammable, hydrophobic, unshrinkability, etc.) of the product. Cotton, wool and synthetic fabrics are made in different finishing processes. Finishing processes are composed of first and last process classify by material contents. First finishing processes are mercerising, singeing, carbonization, alkali treatment and etc. Last processes are composed of dyeing, printing and last chemical finish operations just as wet and dry process. Wet finishing processes; the finishing process in which the textile material is treated with a liquid. In the wet finishes, the performance of the fabric changes rather than the appearance of the fabric. Some of those are softening finish, hard attitude finish, plump finishing, foundry finishing, wrinkle removal, dirt and waterproofing, flame retardant. Dry finishing processes are the finishing processes performed without using any chemicals. Some of these are sanfor, calendering, sueding, embossing, raising, scrub and shearing.

\section{An analysis on Effects of Fabric Selection Parameters}

In this section, different models were examined and evaluated in order to observe the effect of fabric selection parameters on the design. Fabric analyzes were carried out through the designer illustrations of the fashion designer Candan TULGA. Illustrations are about to the inner life of women wearing headscarves in Istanbul outside the stereotypes of the west. In 


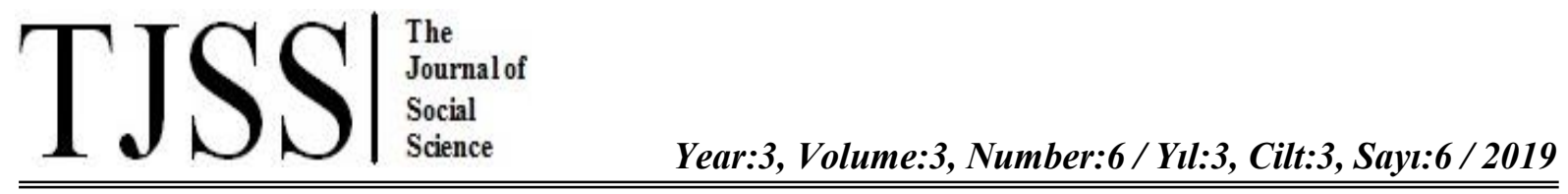

design phase, manipulation techniques were used like as gathering, draping, and shirring and in addition ribbon and cord are used as materials.

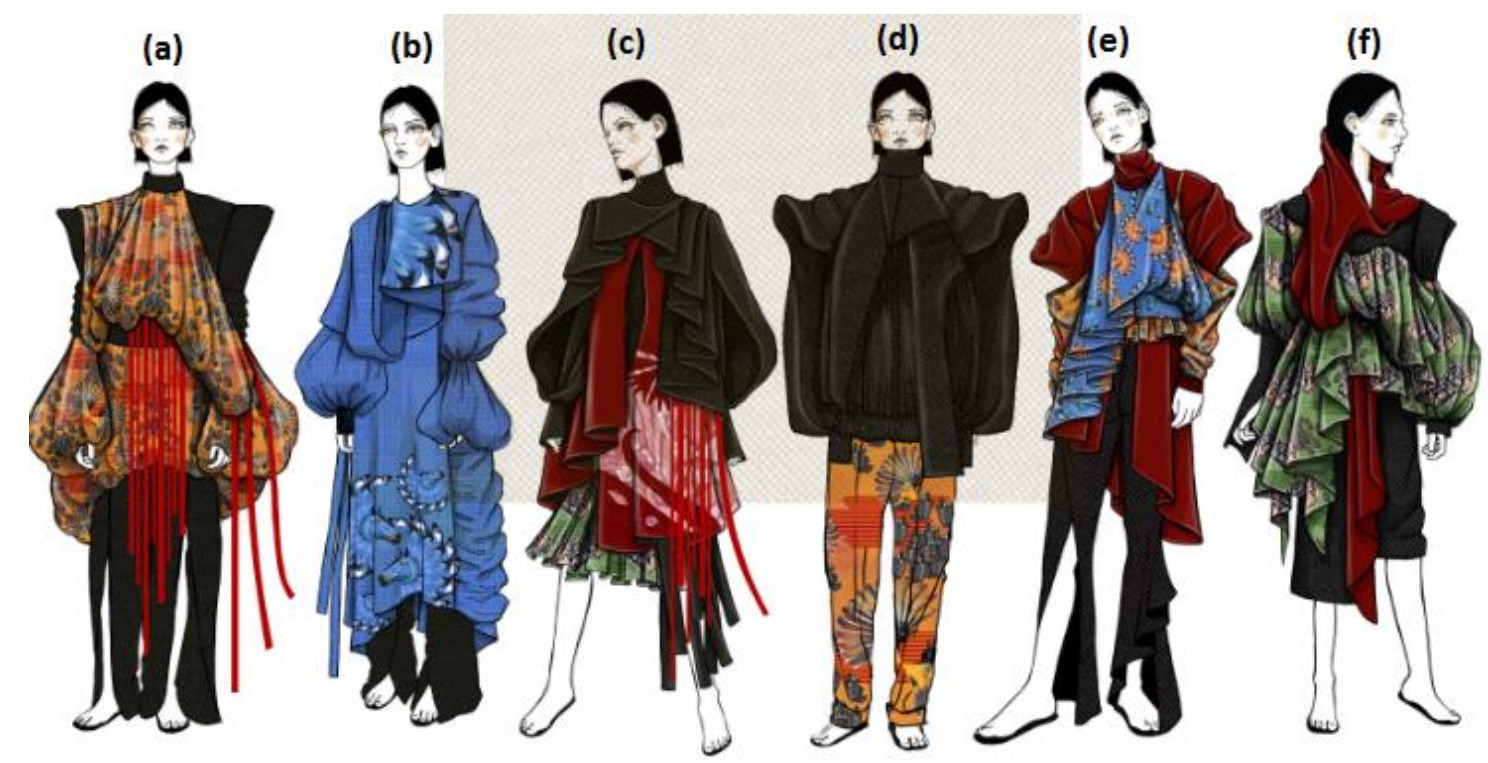

Picture 1. Illustrations about Women Wearing Headscarves in Istanbul

For picture 1 (a), drape and bending properties of the fabric are important for comfort and design image. Fabric gathering which on-going to abdominal from neck region were sewn in an equal interval. This top fabric is polyester and has phoenix prints which expressive on freedom of women. The satin ribbons that come down from the chest area are made of polyester with a narrow woven. For the interior part, black cotton/polyester overall is located and create a movement with a slit in knees. By giving the volume and depth of the garment, free form is given with the effect of the pattern on the silhouette. The garment consists of two parts and can be used as a whole in both parts in terms of the balance of texture, colour, and shape.

For Picture 1 (b), shirring and drape techniques were used in puff sleeve and hem in blue top fabric. This fabric is polyester and has flying horse prints which expressive on stereotypes of the west. The similarity in 1 (a), satin ribbons on-going to ankle from waist part. By creating different manipulations on the fabric, the colour composition of the garment is formed. In addition to experimenting on silhouette features, experimental clothes were created with new searches.

For picture 1 (c), fabrics were used with one on the top of the other with folding and draping. For the interior part, cotton/polyester knife pleated skirt, which has fox print for expression independence, is located. Top poncho fabric has fibers derived from spun polyester like as scuba knit fabric with $40 \%$ stretch cross direction and $10 \%$ stretch vertically. Red satin ribbons descend to ankle from waist part and are made of polyester with a narrow woven. It is observed that the design has a layout and rhythm in itself. This rhythm was repeated and helped to emphasize the design and brought it forward.

For Picture 1 (d), for turtleneck sweater, oversize garment pattern was used with scuba knit fabric. The woman's power was tried to be represented with fabric folding and gathering at 


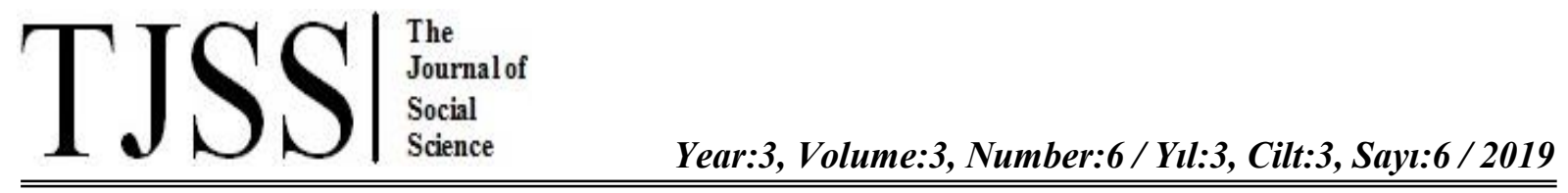

shoulders. The pegged pant have phoenix prints which expressive on freedom of women and is made of cotton/polyester fabric like as 1 (a) upper part. In pant, the print design has reinforced the design by repeating the colour concentrations in a certain rhythm.

For Picture 1 (e), the top blouse was designed with shirring and folding from neck to abdomen and aimed to reflect the sufferings of women. In addition, blouse consists of two parts, the upper part fabric is made of polyester and has flying horse prints which expressive on stereotypes of the west. The inner part fabric is polyester and have phoenix prints which expressive on freedom of women like as 1 (a) top part and (d) pant. Similarity in 1(a), black cotton/polyester overalls is located and create a movement with a slit in knees.

For Picture 1 (f), shirring, draping, and folding techniques were used in the upper part fabric which has fox print for expression independence such as 1 (c). The fabric is produced of polyester yarns and hanged to waist on the purpose of explain to women's responsibilities. For the inner part, cotton/polyester black bermuda overall is parted.

\section{Conclusion}

The design is composed of elements such as colour, material, texture, form, and character. The designer holds together these independent concepts for strengthening the design.

The most important role of design is the correct selection and use of fabric and material. Functionalization and characterization of clothing fabric have gained much attention in recent years because of the change in fashion perception.

In this study, structures, contents, and compositions of fabrics used in garment design were examined and were analyzed the illustrations of the designer Candan Tulga. As a result of evaluations, it was concluded that colour composition, pattern, fiber content, yarn formation and manipulation techniques should be in a certain harmony and rhythm in the fabric in order to provide efficiency in the design. The use of fabric manipulation techniques in relation to the subject to be explained has brought depth to the design. The relationship between design and fabric at all points is an inseparable whole

\section{References}

Renfrew E. \& Renfrew C. (2016), Developing a Collection, ISBN 978-2-940373-95-6, pp 1617.

Akpınarlı F. \& Bulat F. (2016), Tekstil Yüzeylerinin Manipülasyonu Ve Dijital Transfer Bask1 Denemeleri Motif Akademi Halkbilimi Dergisi, 9 (17), pp 167-186.

Gursoy A.T. (2010), Giyim Kültürü ve Moda, Türkiye Tekstil Sanayi İşverenleri Sendikası, İstanbul.

http://www.tdk.gov.tr/ (05.03.2019)

Yurdakul A \& Atav R. (2004), Genel Terbiye Teknolojisi,Emel Akın Meslek Yüksekokulu, Bornova/IZMIR.

Baser İ. (2002), Elyaf Bilgisi, Marmara Üniversitesi, ISBN: 975-400-075-1, pp 12-25. 